\title{
Synaptic Interactions of Late-Spiking Neocortical Neurons in Layer 1
}

\author{
Zhiguo Chu, ${ }^{1}$ Mario Galarreta, ${ }^{1}$ and Shaul Hestrin ${ }^{1,2}$ \\ Departments of ${ }^{1}$ Comparative Medicine and ${ }^{2}$ Neurology and Neurological Sciences, Stanford University School of Medicine, Stanford, \\ California 94305-5342
}

Layer 1 of the neocortex is an important zone in which synaptic integration of inputs originating from a variety of cerebral regions is thought to take place. Layer 1 does not contain pyramidal cells, and several histochemical studies have suggested that most layer 1 neurons are GABAergic. However, although layer 1 neurons could be an important source of inhibition in this layer, the synaptic action of these neurons and the identity of their postsynaptic targets are unknown. We studied the physiological properties and synaptic interactions of a class of cells within layer 1 called late-spiking (LS) cells. The dendrites and axons of layer 1 LS cells were confined primarily to layer 1 . Using paired recording, we showed that LS cells formed GABAergic connections with other LS cells as well as with non-LS cells in layer 1 and with pyramidal cells in layer $2 / 3$. We also found that layer $2 / 3$ pyramidal neurons provide excitatory inputs to LS cells. It has been suggested previously that GABAergic neurons belonging to the same class in the cortex are electrically coupled. In agreement with that hypothesis, we found that LS cells were interconnected by electrical coupling (83\%), whereas electrical coupling between LS cells and non-LS cells was infrequent (2\%). Thus, we provide evidence showing that a group of GABAergic neurons within layer 1 are specifically interconnected by electrical coupling and can provide significant inhibitory inputs to neurons in layer 1 and to distal dendrites of pyramidal cells.

Key words: neocortex; layer 1; inhibition; electrical coupling; late-spiking cells; neurogliaform cells

\section{Introduction}

Layer 1 is a unique layer in the neocortex because it lacks pyramidal neurons. Layer 1 contains axons originating from pyramidal and nonpyramidal neurons located in layers 2-6 and also from other regions (Vogt, 1991), including feedback projections from higher cortical areas (Felleman and Van Essen, 1991) and thalamocortical axons from specific and nonspecific thalamic nuclei (Mitchell and Cauller, 2001; Llinas et al., 2002). Thus, it has been suggested that layer 1 integrates inputs from high-order cortical and thalamic areas (Cauller and Kulics, 1991; Mitchell and Cauller, 2001; Llinas et al., 2002).

The axons in layer 1 are predominantly glutamatergic and GABAergic but also include cholinergic, noradrenergic, and serotoninergic axons (Vogt, 1991), and their main targets are the apical dendritic tufts of pyramidal cells in layers 2-6. In addition to projecting input axons and dendrites of layers 2-6 neurons, layer 1 also contains nonpyramidal neurons (DeFelipe and Jones, 1988). The morphological appearance of layer 1 neurons and the presence of GABAergic markers suggest that they are inhibitory cells (Gabbott and Somogyi, 1986; DeFelipe and Jones, 1988; Winer and Larue, 1989; Li and Schwark, 1994; Hestrin and Armstrong, 1996; Zhou and Hablitz, 1996a). Thus far, however, the inhibitory action of layer 1 neurons has not been demonstrated, and their postsynaptic targets have not been identified. Inhibition in layer 1 could be highly effective in governing the excitatory

Received Sept. 4, 2002; revised 0ct. 8, 2002; accepted 0ct. 15, 2002.

This work was supported by National Institutes of Health Grants EY-12114 and EY-09120. We thank Veronika Zsiros for helpful discussions and Rachel Hestrin and Jane Li for Neurolucida reconstructions.

Correspondence should be addressed to Dr. Shaul Hestrin, Department of Comparative Medicine, Stanford University School of Medicine, 300 Pasteur Drive, R314, Stanford, CA 95305-5342. E-mail: shaul.hestrin@stanford.edu. Copyright $\odot 2002$ Society for Neuroscience $\quad 0270-6474 / 02 / 220096-\bullet \$ 15.00 / 0$ synaptic input in this layer. Thus, it is important to determine directly the synaptic action of layer 1 neurons on their postsynaptic target neurons. Given that extracellular stimulation methods cannot be used to identify the presynaptic cells, we recorded from pairs of neurons consisting of a layer 1 cell together with either other layer 1 neurons or layer $2 / 3$ pyramidal cells.

\section{Materials and Methods}

Slice preparation. Neocortical slices were obtained from Sprague Dawley rats (14-24 d old). Briefly, rats were anesthetized with ketamine (87 $\mathrm{mg} / \mathrm{kg})$ and xylazine $(13 \mathrm{mg} / \mathrm{kg})$ and decapitated. The brain was quickly removed and placed in ice-cold $\left(0-4^{\circ} \mathrm{C}\right)$ extracellular solution containing the following (in mM): $125 \mathrm{NaCl}, 2.5 \mathrm{KCl}, 1.25 \mathrm{NaH}_{2} \mathrm{PO}_{4}, 1.0 \mathrm{MgSO}_{4}$, $2.0 \mathrm{CaCl}_{2}, 26 \mathrm{NaHCO}_{3}, 20$ D-glucose, 0.4 ascorbic acid, 2.0 pyruvic acid, and 4.0 lactic acid. The $\mathrm{pH}$ was maintained by continuous bubbling with a gas consisting of $95 \% \mathrm{O}_{2}$ and $5 \% \mathrm{CO}_{2}$. The brain was hemisected, and a block of cortex was glued to the stage of a Vibratome (VT1000S; Leica, Heidelberg, Germany). Parasagittal cortical slices (300 $\mu \mathrm{m}$ thick, $30^{\circ}$ angle) were cut, transferred to a holding chamber, and incubated at a temperature of $32-34^{\circ} \mathrm{C}$ for $30 \mathrm{~min}$. The slices were maintained at room temperature until they were transferred to the recording chamber. The recording chamber was mounted on the stage of an upright microscope (Axioskop FS-1; Zeiss, Thornwood, NY) equipped with a $40 \times$ water immersion objective.

Cell identification. Nonpyramidal neurons in layer 1 of the visual and somatosensory cortices were selected and identified on the basis of their electrophysiological and morphological properties as detailed below and in Results. Pyramidal neurons in layer $2 / 3$ were identified by their somatic shape, apical dendrite, and pattern of spiking. We used infrared differential interference contrast (DIC) optics to visualize individual neurons. To distinguish cell types in layer 1 , their responses to nearthreshold current injection were examined. Layer 1 late-spiking (LS) neurons were distinguished from other types of layer 1 neurons by electrophysiological criteria (see Results). Other neurons in layer 1 lacking 
these characteristics were classified as non-LS neurons. Initially, random recordings without visual selection were made in layer 1 . Under these conditions, $39 \%$ of the neurons (31 in 79 neurons) were identified as LS neurons. In later studies, neurons with a relatively round soma or multipolar appearance in the middle part of layer 1 were preselected visually as putative LS cells. Their identity was later confirmed on the basis of their electrophysiological properties.

Whole-cell recordings. We recorded from layer 1 neurons and from pyramidal neurons using somatic whole-cell patch-clamp recordings. Patch pipettes were pulled from thin-walled borosilicate glass (outer diameter, $1.5 \mathrm{~mm}$; inner diameter, $1.17 \mathrm{~mm}$; Warner Instruments, Hamden, CT) using a P-87 pipette puller (Sutter Instruments, Novato, CA). Recording pipettes were filled with low-chloride solution [in mM: 140 K-methylsulfate, $6.3 \mathrm{KCl}, 10 \mathrm{HEPES}, 0.2 \mathrm{EGTA}$, 4.0 MgATP, $0.3 \mathrm{GTP}$, and 20 phosphocreatine $(\mathrm{Na})$ ] or high-chloride solution [in mM: 106.3 K-methylsulfate, $40 \mathrm{KCl}, 10 \mathrm{HEPES}, 0.2 \mathrm{EGTA}, 4.0 \mathrm{MgATP}, 0.3 \mathrm{GTP}$, and 20 phosphocreatine $(\mathrm{Na})$ ]. $\mathrm{pH}$ was adjusted to 7.3 and $290 \mathrm{mOsm}$. Pipettes had resistances of 3-4 M $\Omega$. Current- and voltage-clamp recordings were performed using Axopatch-200B amplifiers (Axon Instruments, Union City, CA). Current and voltage signals were low-pass filtered at $5 \mathrm{kHz}$ and digitized at 16 bit resolution (ITC-18; Instrutech, Port Washington, NY) and a sampling frequency of $10 \mathrm{kHz}$. The liquid junction potential error was not corrected. In some experiments, DNQX (20 $\mu \mathrm{M}$; Research Biochemicals, Natick, MA) was present in the bath to block AMPA/kainate receptor-mediated synaptic currents. The $\mathrm{GABA}_{\mathrm{A}}$ receptor antagonist (-)bicuculline methiodide (10-20 $\mu \mathrm{M}$; Sigma, St. Louis, $\mathrm{MO}$ ) was bath applied. All recordings were made at a temperature of $33-34^{\circ} \mathrm{C}$.

Data analysis. Data acquisition and data analysis were done using Igor software (WaveMetrics, Lake Oswego, OR). The input resistance and membrane time constant of layer 1 neurons were determined from the average response to a depolarizing pulse ( $\sim 5 \mathrm{mV}, 400-600 \mathrm{msec}, 20-50$ $\mathrm{pA}$ ). Spike amplitude and the afterhyperpolarization potential (AHP) amplitude were measured relative to the spike threshold. The time interval between the peak of the action potential and the minimum of the AHP was measured in traces containing a single spike. Spike frequency adaptation was measured as the ratio of the third to the first interspike interval (ISI) in traces containing four to five spikes. To identify chemical synaptic transmission, action potentials were generated in the presynaptic neurons using brief pulses $(2-3 \mathrm{msec})$ of suprathreshold currents at a frequency of $0.25-0.166 \mathrm{~Hz}$. In the presence of electrical coupling, a GABAergic connection or its absence was detected by comparing the postsynaptic responses obtained at membrane potentials of -50 and $-90 \mathrm{mV}$ (in low internal chloride). The step coupling coefficient was calculated as the ratio of the voltage change in the noninjected cell to that in the injected cell. The coupling coefficient of the spikelet was calculated as the ratio of the action potential amplitude (using the threshold as reference) and the spikelet amplitude (using the baseline as reference). The junctional conductance between electrically coupled LS cells was estimated from $G_{j}=\left(1 / R_{2}\right) \times \mathrm{CC} /(1-\mathrm{CC})$, where CC is coupling coefficient and $R_{2}$ is input resistance of the noninjected cell. Unless otherwise stated, data are presented as mean \pm SEM.

Histology. To study the morphology of layer 1 neurons, $0.5 \%$ biocytin was included in the pipette solution. The slices containing biocytin-filled cells were fixed with $4 \%$ paraformaldehyde. Standard avidin-biotinylated-horseradish peroxidase complex (ABC; Vector Laboratories, Burlingame, $\mathrm{CA}$ ) and the 3,3'-diaminobenzidine reaction procedure were used. Neurolucida (MicroBrightField, Williston, VT) was used for reconstruction of layer 1 neurons. To study parvalbumin immunostaining, the slices were fixed overnight and then washed with PBS solution. Subsequently, they were incubated in a solution containing $1 \%$ Triton X-100, $2 \%$ normal goat serum, and 2\% BSA for $4 \mathrm{hr}$, followed by overnight incubation with rabbit anti-parvalbumin (1:3000; pv28; Swant, Bellinzona, Switzerland). Afterward, the slices were washed with PBS and incubated with Alexa-555 goat anti-rabbit IgG (1:300; A-21428; Molecular Probes, Eugene, OR) for $3 \mathrm{hr}$. The immunoreactive cells were examined under appropriate filter systems (Zeiss).
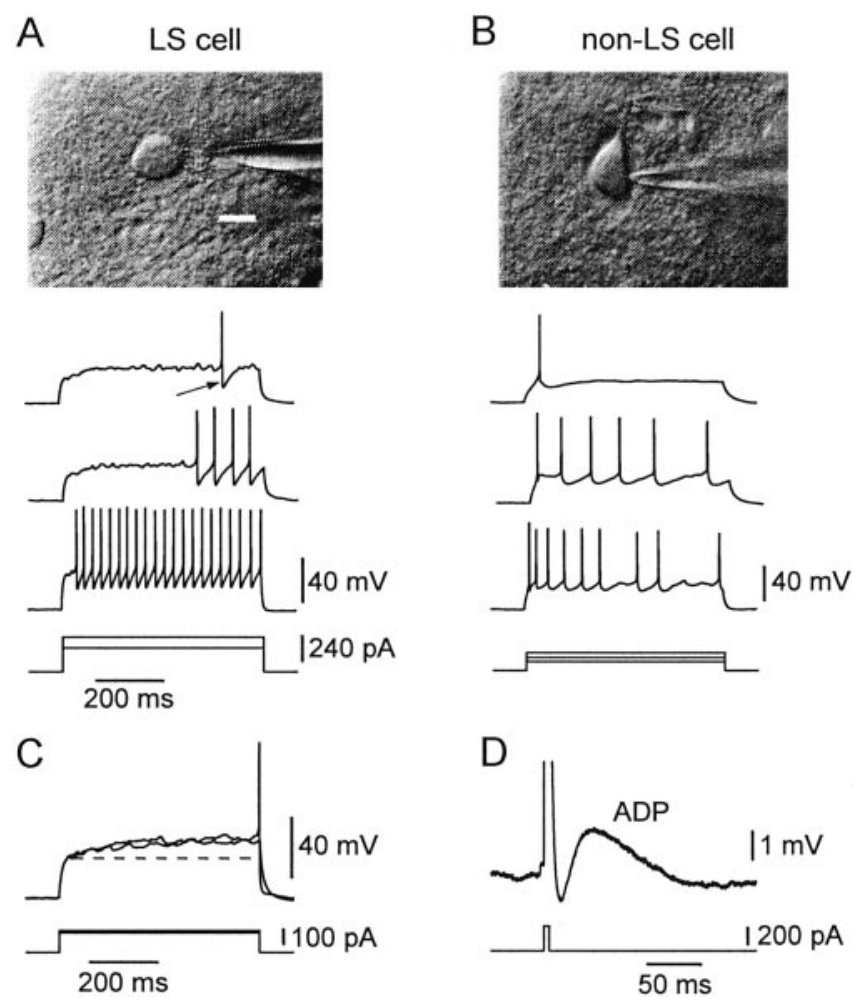

Figure 1. Electrophysiological properties of $L S$ cells in layer 1. A, Top, DIC-infrared video microscopy image of an LS cell. Scale bar, $10 \mu \mathrm{m}$. Bottom, Firing pattern of the same cell in response to the injection of depolarizing current pulses. The two top traces were produced with the same magnitude of current injection. Note the delayed firing during the current injection, the single-component fast AHP (arrow), and the lack of spike frequency adaptation in the near-threshold discharge (middle trace). Resting $V_{\mathrm{m}},-62 \mathrm{mV}$. B, DIC-infrared video microscopy image (top) and pattern of firing in response to current injection (bottom) of a non-LS cell. Resting $V_{\mathrm{m}},-81 \mathrm{mV}$. Calibration as in $A$. C, Current-clamp recording from an $\mathrm{LS}$ cell in response to two near-threshold current injections. Note the slow depolarizing ramp commonly observed in LS cells under these conditions. An action potential was produced at the end of the pulse in one of the traces. Resting $V_{\mathrm{m}},-69 \mathrm{mV}$. D, Recording from an $\mathrm{LS}$ cell. A single action potential induced by a brief current injection ( $300 \mathrm{pA}, 5 \mathrm{msec}$ ) was followed by an afterdepolarization $(A D P)$. The action potential has been truncated. Resting $V_{\mathrm{m}},-72 \mathrm{mV}$.

\section{Results}

\section{Late-spiking cells in layer 1}

In contrast to other cortical layers containing both pyramidal and nonpyramidal neurons, layer 1 contains only nonpyramidal cells. Layer 1 neurons are a heterogeneous group and include neurons whose axons project vertically outside of layer 1 and neurons whose axons are restricted primarily to layer 1 (DeFelipe and Jones, 1988; Hestrin and Armstrong, 1996; Zhou and Hablitz, 1996a). We identified a group of neurons within layer 1 on the basis of their electrophysiological responses to current injection. We called these neurons LS cells because their properties were similar to those reported previously for layers 2-6 LS cells (Kawaguchi, 1995; Kawaguchi and Kubota, 1997). LS cells were characterized by the following properties. When we injected prolonged near-threshold current pulses (600 msec), layer $1 \mathrm{LS}$ cells typically generated a ramp, followed by a delayed spike (Fig. $1 A, C)$. Suprathreshold current injection produced discharges of nonadapting spikes (third ISI/first ISI $=1.1 \pm 0.01 ; n=207$ ). After an action potential, during the injection of a prolonged current pulse, LS cells exhibited a single-component fast AHP (Fig. $1 \mathrm{~A}$, arrow). The minimum of the AHP of LS cells occurred at $<10$ msec intervals after the action potential peak (average, $4.9 \pm$ $0.1 \mathrm{msec} ; n=207)$. In addition, LS cells displayed a depolarizing 
waveform after spikes generated by injection of a brief current pulse, called an afterdepolarization (Fig. 1D) (Hestrin and Armstrong, 1996; Zhou and Hablitz, 1996b; Budde and White, 1998). Neurons not showing these characteristics were heterogeneous and were called collectively non-LS cells (Fig. $1 B$ ). Non-LS cells had slower AHP $(19.3 \pm 0.7 \mathrm{msec} ; n=154)$ than LS cells (Fig. $1 B)$. In addition, non-LS cells exhibited spike frequency adaptation during prolonged current injection (Fig. $1 B$ ) (third ISI/first ISI $=1.9 \pm 0.17 ; n=154$ ).

We found that the average input resistance of LS cells was $245.9 \pm 5.5 \mathrm{M} \Omega(n=163)$, and their membrane time constant was $19.9 \pm 1.1 \mathrm{msec}(n=78)$. In addition, the average frequency of the near-threshold discharges of LS cells was $16.1 \mathrm{~Hz}(n=$ 160 ). This value is smaller than that reported previously for fastspiking (FS) cells in lower cortical layers, which is typically $>50$ $\mathrm{Hz}$ (Galarreta and Hestrin, 1999). In addition, FS cells in layers 2-6 express the calcium-binding protein parvalbumin (Kawaguchi and Kubota, 1997), but layer 1 neurons are parvalbumin immunonegative (data not shown). Thus, LS cells in layer 1 represent a different class than FS cells.

\section{Morphology of LS cells}

LS and non-LS cells were filled with biocytin during the recording to reconstruct their structure (Fig. 2) (LS, $n=6$; non-LS, $n=4$ ). We found that cells identified on the basis of electrophysiological characteristics as LS cells had a dense local axon extending horizontally (Fig. 2,A1-A3). The somata of LS cells were multipolar, and their dendrites were radial, short, and aspinous. Both dendrites and axons of LS cells were included primarily in layer 1 . This morphology is similar to that described previously for neurogliaform cells in layer 1 (DeFelipe and Jones, 1988; Anderson et al., 1992; Hestrin and Armstrong, 1996). In other cortical layers, LS cells have been shown to include neurogliaform cells (Kawaguchi, 1995; Kawaguchi and Kubota, 1997). Non-LS cells had a heterogeneous morphological appearance. In general, the axon belonging to the non-LS cells was diffuse, projecting in both layer 1 and the lower layers (Fig. 2B).

\section{Synaptic connections between LS cells and pyramidal neurons}

Neurons in layer 1 express GABAergic markers, suggesting that they are inhibitory interneurons (Gabbott and Somogyi, 1986; Beaulieu et al., 1992; Li and Schwark, 1994). However, no direct confirmation of the inhibitory function by layer 1 neurons has been demonstrated. To test the synaptic function by LS layer 1 neurons at pyramidal cells, we recorded from pairs consisting of a presynaptic LS cell and a layer $2 / 3$ pyramidal neuron (Fig. $3 \mathrm{~A}$ ) (10 connected pairs, 142 pairs tested; intersomata distance, 75$180 \mu \mathrm{m})$. As illustrated in Figure 3, at a postsynaptic membrane potential of $-48 \mathrm{mV}$, a presynaptic action potential produced a hyperpolarizing IPSP $(n=5)$. When the membrane potential was kept at $-93 \mathrm{mV}$, the postsynaptic response was depolarizing (low internal chloride). These results show that LS cells are inhibitory neurons and suggest that the postsynaptic response could reflect an increase to chloride conductance. At connections between a presynaptic LS cell and layer $2 / 3$ pyramidal neurons, the average rise time $(10-90 \%)$ of the IPSPs was $12.6 \pm 7.0 \mathrm{msec}(n=10)$. The IPSPs were fit with an exponential function, and the time constant was $27.2 \pm 11.1 \mathrm{msec}$ (mean $\pm \mathrm{SD} ; n=3$ ) using low chloride internal solution at depolarizing potentials $(-45$ to -55 $\mathrm{mV}$ ) and $27.7 \pm 6.6 \mathrm{msec}($ mean $\pm \mathrm{SD} ; n=4)$ using high internal chloride at approximately $-90 \mathrm{mV}$. Thus, these data suggest that
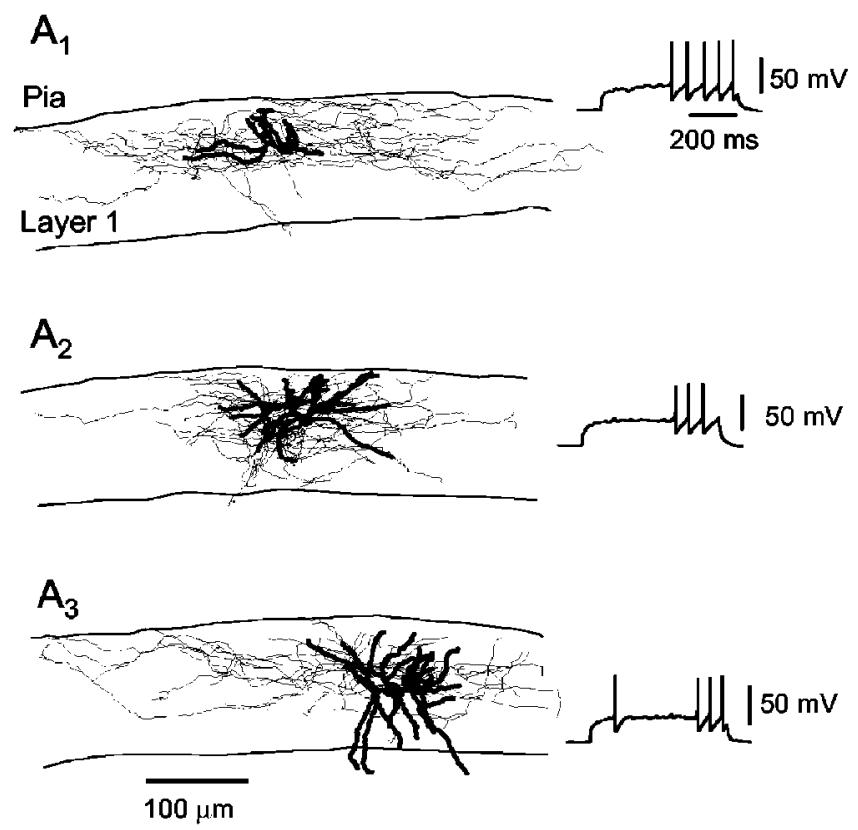

B

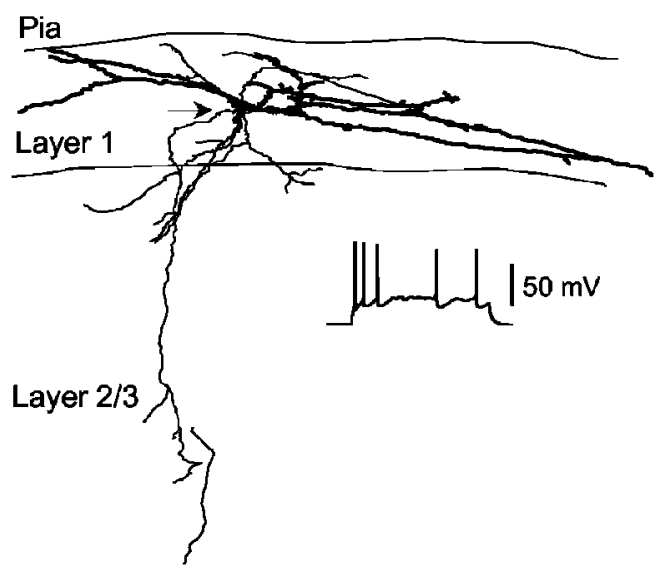

Figure 2. Morphology of nonpyramidal cells in layer 1 . $A$, Neurolucida reconstruction of three $L S$ cells $\left(A_{1}-A_{3}\right)$ filled with biocytin. Dendrites are illustrated with thick traces, and axons are illustrated with thin traces. Note the extensive axonal arborizations distributed around the soma and extending horizontally within layer 1. Insets, Pattern of firing of the reconstructed neurons in response to near-threshold current injections. $B$, Neurolucida reconstruction of a non-LS cell. The axon, whose origin is indicated by the arrowhead, extends into lower layers of the neocortex. Inset, Pattern of firing in response to a depolarizing current injection.

LS cells of layer 1 make chloride-dependent inhibitory synaptic inputs at their pyramidal cells targets.

It has been shown previously that layer 1 neurons receive excitatory synaptic inputs (Hestrin and Armstrong, 1996; Zhou and Hablitz, 1997). One possible source of these excitatory inputs to layer 1 neurons could originate from layer $2 / 3$ pyramidal neurons whose axons send collateral branches into layer 1 . In agreement with that suggestion, we found that LS cells receive EPSPs from presynaptic layer $2 / 3$ pyramidal cells (Fig. $3 B$ ). At connections between a presynaptic layer $2 / 3$ pyramidal cell and a postsynaptic LS cell, the average rise time (10-90\%) of the EPSPs was $2.6 \pm 1.6$ $\operatorname{msec}(n=3)$, and the average EPSP decay time constant was $10.0 \pm 2.1 \mathrm{msec}$ (mean $\pm \mathrm{SD} ; n=3$ connected pairs; 101 pairs tested). Figure $3 B$ illustrates an EPSP at the pyramidal cell-to-LS 

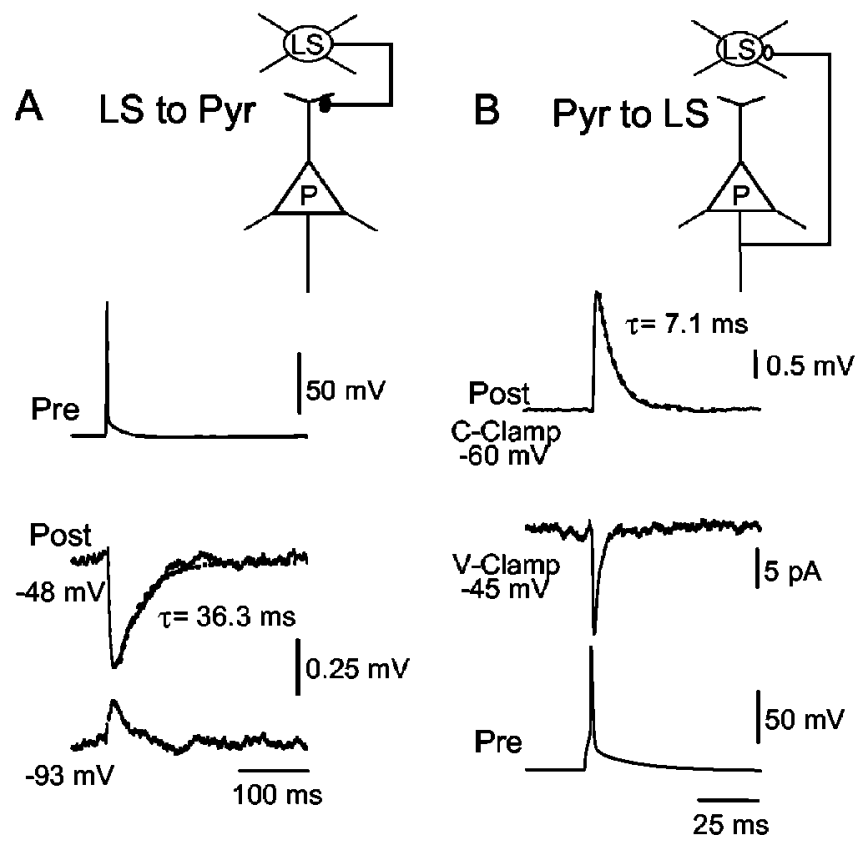

Figure 3. Synaptic connectivity between layer $1 \mathrm{LS}$ neurons and layer $2 / 3$ pyramidal (Pyr) cells. $A$, Paired recording between a presynaptic $\mathrm{LS}$ cell in layer 1 (Pre) and a postsynaptic pyramidal cell in layer 2/3 (Post). Top, Schematic drawing of the pair. Top trace, Presynaptic action potential induced by a brief current injection. Middle trace, Unitary IPSP recorded at a $V_{\mathrm{m}}$ of $-48 \mathrm{mV}$. Dotted line, Single-exponential fit $(\tau=36.3 \mathrm{msec})$. Bottom trace, unitary IPSP recorded at a $V_{\mathrm{m}}$ of $-93 \mathrm{mV}$ (low internal chloride). Note that the unitary IPSP reversed its polarity and became depolarizing. The capacitative surge in the postsynaptic cell was blanked. $B$, Paired recording between a presynaptic layer $2 / 3$ pyramidal neuron (bottom trace, Pre) and a postsynaptic layer $1 \mathrm{LS}$ cell. Top, Schematic drawing of the pair. Top trace, Unitary EPSP recorded at a $V_{m}$ of $-60 \mathrm{mV}$. C-Clamp, Current clamp; V-Clamp, voltage clamp. Dotted line, Singleexponential fit ( $\tau=7.1 \mathrm{msec}$ ). Middle trace, Unitary EPSC recorded under voltage-clamp mode (holding potential, $-45 \mathrm{mV}$ ). Traces in $A$ and $B$ are the average of $>100$ trials (stimulation frequency, $0.25 \mathrm{~Hz}$ ).

connection that had an exponential time constant of $7.1 \mathrm{msec}$. Under voltage clamp at a holding potential of $-45 \mathrm{mV}$, the EPSC of this connection had a decay time constant of $3.2 \mathrm{msec}$ (Fig. $3 B$ ).

\section{Synaptic connections between LS cells and non-LS cells}

In addition to dendrites of pyramidal cells from lower layers, LS cells could also target both other LS cells and non-LS cells in layer 1. We found that LS cells provide inhibitory inputs to non-LS cells in layer 1 ( $n=19$ pairs connected; 107 pairs tested) (Fig. $4 A$ ). The synaptic inputs were hyperpolarizing when recorded with low-chloride-containing pipettes at a depolarized membrane potential (Fig. $4 A)(n=4)$. When we used high-chloridecontaining pipettes, the response was reversed, and the IPSPs were depolarizing at membrane potentials of -60 to $-45 \mathrm{mV}$ (Fig. $4 B$ ). The IPSPs of LS-to-non-LS connections were slow, the average decay time constant was $31.2 \pm 3.6 \mathrm{msec}(n=14)$, and the rise time was $10.6 \pm 1.0 \mathrm{msec}(n=17)$. Furthermore, we also found that non-LS cells made inhibitory connections with layer 1 LS cells ( $n=2$ pairs) and layer $2 / 3$ pyramidal cells $(n=4$ pairs) and receive excitatory connections from layer $2 / 3$ pyramidal cells ( $n=2$ pairs).

Electrical coupling and inhibitory connections among LS cells We studied the synaptic interactions among LS cells in layer 1. It has been suggested that, in the cortex, GABAergic cells belonging to the same class are interconnected via electrical coupling (Galarreta and Hestrin, 1999, 2001b; Gibson et al., 1999). To test

\section{LS to non-LS}

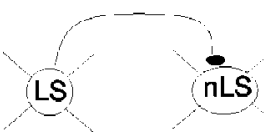

A

Low $\left[\mathrm{Cl}^{-}\right]_{\mathrm{i}}$

B High $\left[\mathrm{Cl}^{-}\right]_{\mathrm{i}}$
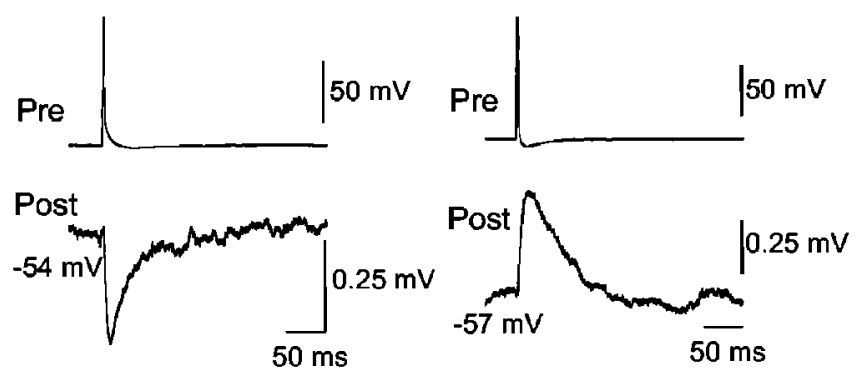

Figure 4. LS cells make inhibitory GABAergic chemical synapses to other interneurons in layer 1. A, B, Paired recordings from two pairs consisting of a presynaptic $L S$ cell (Pre) and a postsynaptic non-LS cell (Post) in layer 1. A, A hyperpolarizing unitary IPSP was recorded when the postsynaptic cell was kept at a $V_{\mathrm{m}}$ of $-54 \mathrm{mV}$ and a low-chloride internal solution was used $\left(E_{C \mid}\right.$ of $\left.-76 \mathrm{mV}\right) . B$, The polarity of the unitary IPSP changed when the postsynaptic cell was filled with a high-chloride internal solution $\left(E_{C l}\right.$ of $\left.-30 \mathrm{mV}\right)$.

whether this notion applies to LS cells in layer 1, we recorded from pairs of LS cells. We found that $83 \%$ of LS cell pairs were electrically coupled ( $n=49$ coupled; 59 pairs tested) and that $26.2 \%$ of the LS cell pairs were chemically connected $(n=17$ pairs connected; 65 pairs tested). When both electrical and chemical connections were present, we found a dual-component postsynaptic response exhibiting a depolarizing phase, followed by a hyperpolarizing phase $\left(V_{\mathrm{m}}=-50 \mathrm{mV}\right)$ (Fig. $\left.5 A\right)$. When high-chloride-containing pipettes were used, the IPSP was depolarizing (Fig. $5 B)(n=9 ; 33$ pairs tested). These data indicate that LS cells are interconnected by inhibitory synapses. In addition, in four experiments, we found that bicuculline $(20 \mu \mathrm{M})$ blocked the IPSP (Fig. $5 C$ ). The IPSP at LS-to-LS connections was slow; the decay time constant was $46.7 \pm 3.8 \mathrm{msec}(n=14)$.

To study the electrical coupling among LS cells in isolation, we recorded from pairs of LS cells (Fig. 6A). Under current-clamp conditions, we injected long steps of either hyperpolarizing or depolarizing currents in one cell. As shown in Figure $6 B$, the noninjected cells reflected the response of the injected cell. The electrical coupling that we found among LS cells was bidirectional at the range of membrane potential that we studied. The average coupling coefficient of pairs of LS cells was $4.5 \pm 0.8 \%$ (range, $0.53-16.9 \% ; n=31$ ).

To test for the specificity of the electrical coupling, we recorded from pairs consisting of an LS cell and a non-LS cell (Fig. $7 A, B)$. Of 93 pairs tested, only two LS-to-non-LS pairs were electrically coupled. Overall, we found that the frequency of electrical coupling among LS-to-LS pairs was 83\% (Fig. 7C) (49 of 59), whereas the probability of electrical coupling at LS-to-non-LS pairs was only $2 \%$ ( 2 of 93 ). These results indicate that electrical coupling is highly specific, as has been found in other layers of the neocortex (Galarreta and Hestrin, 2001b).

\section{The properties of electrical coupling}

We compared the coupling coefficients at each LS-to-LS pair by injecting current to cell 1 or cell 2 (Fig. $8 A$ ). The estimated bidirectional coupling coefficients were similar, suggesting that the electrical junctions were located at similar electrotonic distances from the somata. We found that the magnitude of the coupling 


\section{LS to LS}

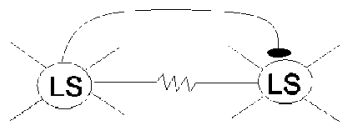

A Low $[\mathrm{Cl}]_{\mathrm{i}}$
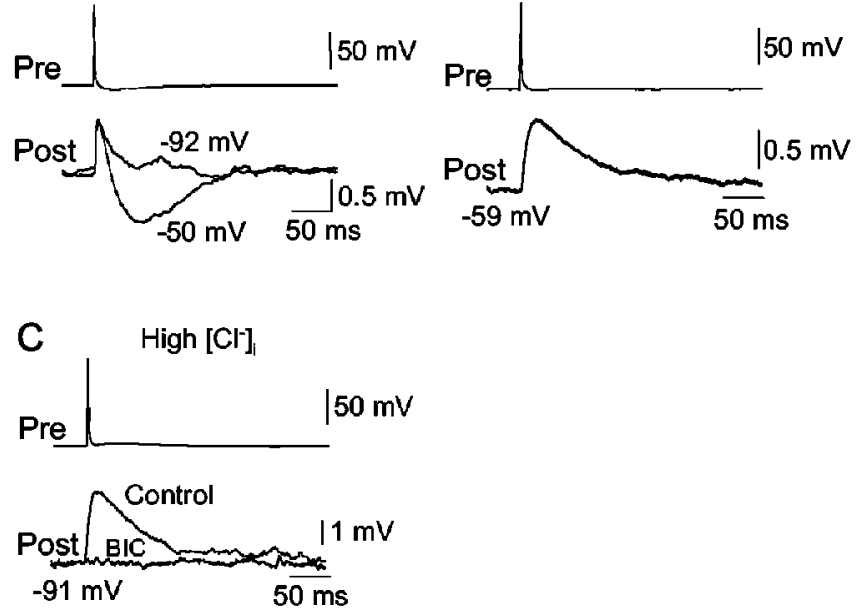

Figure 5. Paired recording between a pair of $L S$ cells connected via both electrical and chemical synapses. A, At a $V_{\mathrm{m}}$ of $-50 \mathrm{mV}$, the postsynaptic potential (bottom traces, Post) was biphasic, with a depolarizing component mediated by the electrical connection and a hyperpolarizing component reflecting the IPSP. When the postsynaptic response was recorded at $-92 \mathrm{mV}$, the unitary IPSP was reduced dramatically, whereas the electrically mediated depolarization remained unmodified (low-chloride internal postsynaptic solution). Top trace, Presynaptic action potential (Pre) in response to a brief depolarizing current injection. B, Paired recording from a different pair of $L S$ cells connected by electrical and chemical synapses. A depolarizing unitary IPSP was recorded when the postsynaptic cell was kept at a $V_{m}$ of $-59 \mathrm{mV}$ and a high-chloride internal solution was used. C, Paired recording from a pair of $L S$ cells connected only chemically. The depolarizing IPSP recorded at a $V_{\mathrm{m}}$ of $-91 \mathrm{mV}$ (Control) was blocked in the presence of bicuculline ( $B / C$ at $20 \mu \mathrm{m}$ (high-chloride internal solution). Traces in $A$ are the average of 100 trials. Traces in $B$ and $C$ are the average of $16-24$ trials. The coupling coefficient of the pair shown in $A$ was $14 \%$, and that shown in $B$ was $8.3 \%$. The pair shown in $C$ was not electrically coupled.

coefficient seems to depend on the distance between the LS cell somata. When the distance was $<40 \mu \mathrm{m}$, the range was higher than that measured when the distance was $40-120 \mu \mathrm{m}$ (Fig. $8 B$ ). The average coupling conductance (see Materials and Methods) was $178.8 \pm 31.5 \mathrm{pS}$ ( $n=31$ pairs; range, $32.6-642.6 \mathrm{pS})$.

In addition to transmission of low-frequency signals among coupled cells, presynaptic spikes could also affect an electrically coupled cell. To record spikelets, we selected LS-to-LS pairs that did not have GABAergic connections (see Materials and Methods). The "presynaptic" cell was depolarized by injection of steady current-producing spikes. We used these spikes to obtain the spike-triggered average of the "postsynaptic" response (Fig. $8 C)$. Under these conditions, the spikelet had a fast depolarizing phase, followed by a larger hyperpolarizing phase reflecting the presynaptic spike AHP. The ratio of the presynaptic spike to the spikelet amplitude was $0.47 \pm 0.07 \%(n=28)$, and the spikelet latency was $1.0 \pm 0.1 \mathrm{msec}(n=28)$.

\section{Discussion}

In this report, we directly demonstrated that layer 1 neurons of the LS cell class provide inhibitory inputs to pyramidal cells and to layer 1 neurons. Furthermore, we found that LS cells are specifically and highly interconnected by electrical coupling. In addition, we showed that LS cells receive excitatory inputs from layer $2 / 3$ pyramidal neurons.
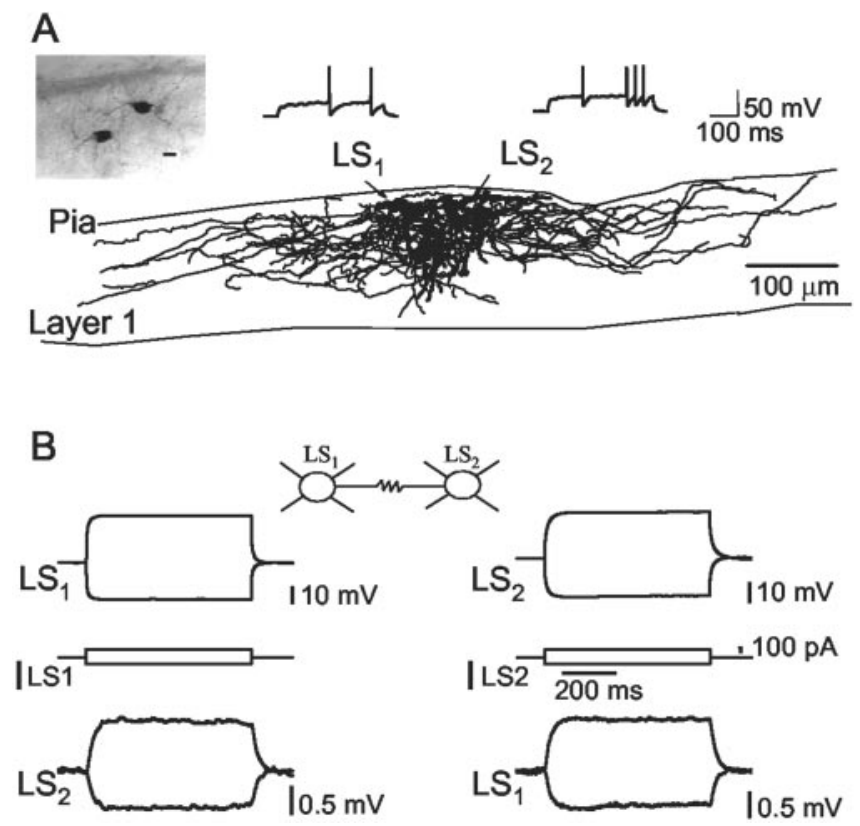

Figure 6. Electrical coupling among layer $1 \mathrm{LS}$ neurons. $A$, Neurolucida reconstruction of a pair of $L S$ cells in layer 1. Dendrites are illustrated with thick traces, and axons are illustrated with thin traces. Left, Photograph illustrating the same pair of cells filled with biocytin. Scale bar (in photomicrograph), $10 \mu \mathrm{m}$. Top insets, Firing pattern of the two $\mathrm{LS}$ cells in response to a pulse of depolarizing current. $B$, Left, Injecting a pulse of depolarizing or hyperpolarizing current in $L S_{1}$ affected the membrane of both $L S_{1}$ and $L S_{2}$. Similarly, injecting current in $L S_{2}$ depolarized or hyperpolarized the membrane of $\mathrm{LS}_{1}$ (right). Data from the pair of cells shown in A. Step coupling coefficients were as follows: $6.65 \%$ in $L S_{1}$-to- $L S_{2}$ and $8.1 \%$ in $L S_{2}$-to- $-S_{1}$. Traces are the average of $>130$ trials.

\section{Late-spiking cells in layer 1}

Although layer 1 is sometimes described as an acellular layer, it was shown by Cajal that layer 1 contains interneurons (DeFelipe and Jones, 1988). Furthermore, Cajal recognized that the layer 1 neurons are heterogeneous. More recent studies revealed that layer 1 neurons express GABAergic markers and that the density of GABAergic neurons in layer 1 is $~ 50 \%$ of that found in layers 2-6 (Gabbott and Somogyi, 1986; Winer and Larue, 1989; Li and Schwark, 1994). Cajal identified previously neurogliaform cells in layer 1 (DeFelipe and Jones, 1988), and, more recently, Martin et al. (1989) recorded visual responses from a layer 1 neuron that morphologically resembles a neurogliaform cell. In this study, we characterized late-spiking cells in layer 1 that have multipolar somata, short dendrites, and a dense local axonal projection that generally remained within layer 1 extending horizontally. The electrophysiological properties of layer 1 LS cells suggest that these cells may be similar to neurogliaform cells in layers 2-6 (Jones, 1984; Kawaguchi, 1995; Kawaguchi and Kubota, 1997).

\section{Inhibitory and excitatory synapses of LS cells}

It was shown previously that layer 1 neurons express GABAergic markers (Gabbott and Somogyi, 1986; Winer and Larue, 1989; Beaulieu et al., 1992; Li and Schwark, 1994). In addition, recent studies showed that extracellular stimulation in layer 1, which may activate layer 1 neurons, could produce inhibition at pyramidal cells (Helmchen et al., 1999; Larkum and Zhu, 2002). Nonetheless, the synaptic action of layer 1 neurons and the identity of their targets remain unknown. The paired-recording data presented here demonstrate directly that LS neurons in layer 1 are indeed inhibitory at several targets, including layer 1 interneurons and pyramidal cells. 

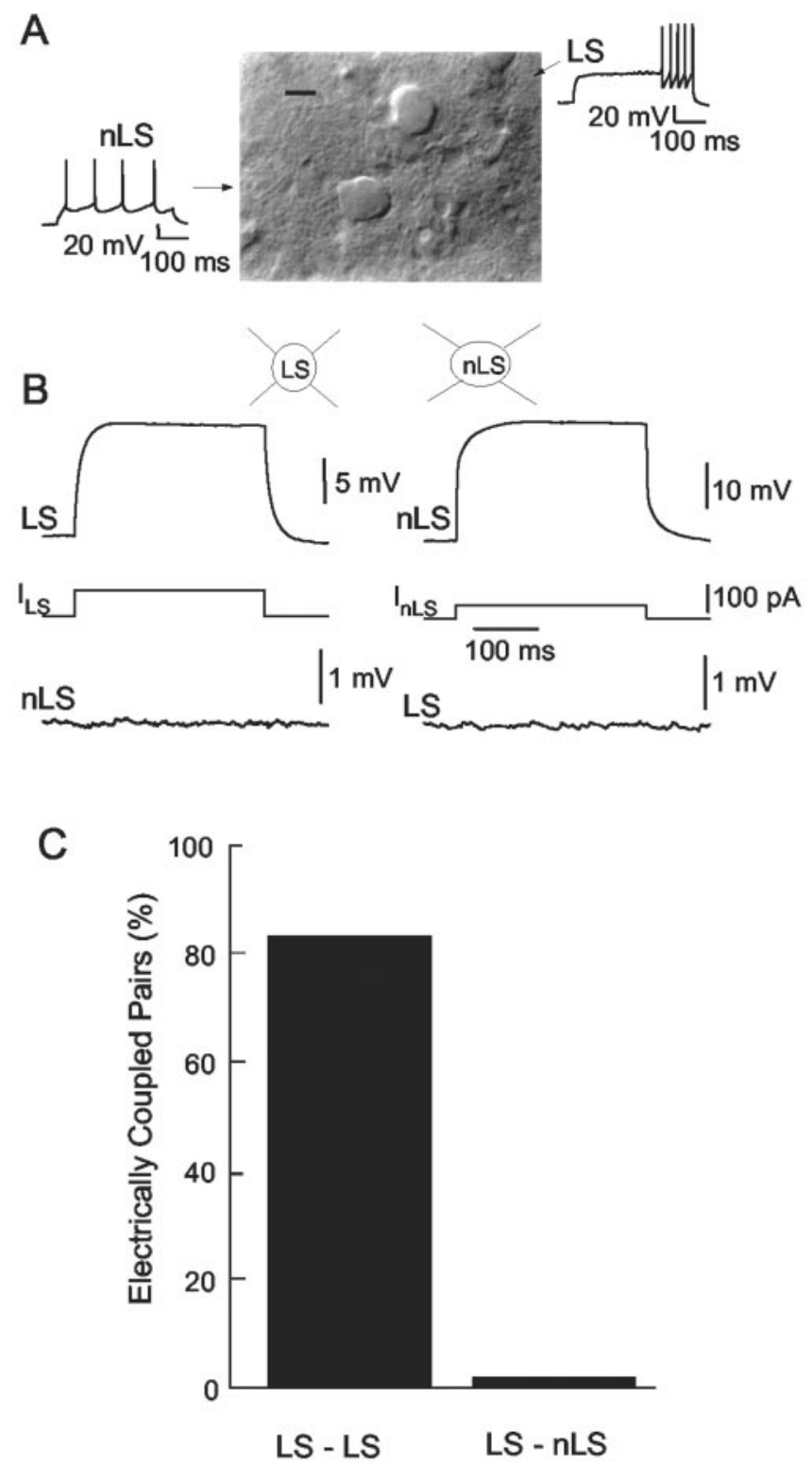

Figure 7. Electrical coupling among nonpyramidal cells in layer 1 is cell type specific. $A$, Photograph of an LS cell and a non-LS ( $n L S$ ) cell simultaneously recorded in layer 1. Scale bar (in photomicrograph), $10 \mu \mathrm{m}$. The insets show their distinct patterns of firing in response to current injection. $B$, Injecting a pulse of depolarizing current in the LS (left) or the non-LS cell (right) did not affect the membrane potential of the noninjected cell. C, Histogram illustrating the percentage of pairs electrically coupled. Note the high rate of electrical coupling among $L S$ cells (83\%; 49 of 59 pairs) in contrast with the very low rate among the pairs consisting of an $L S$ and a non-LS cell (2\%; 2 of 93 pairs).

Presynaptic action potentials in LS cells produced hyperpolarizing responses when the membrane potential of the postsynaptic cell was -50 to $-60 \mathrm{mV}$. These IPSPs were depolarizing when high internal chloride was used, and they were blocked by bicuculline. Thus, these data show that the IPSPs generated by LS cells are mediated by $\mathrm{GABA}_{\mathrm{A}}$ receptors. The rise time and decay time constants of the IPSPs were slow compared with IPSPs generated by FS cells (Geiger et al., 1997; Galarreta and Hestrin, 1999, 2001a; Gibson et al., 1999). Given that the axonal projections of LS cells were confined primarily to layer 1 , it is likely that the synaptic contact of LS and pyramidal cells occurs at distal dendrites, which may produce slow synaptic response. However, it is also possible that the $\mathrm{GABA}_{\mathrm{A}}$ receptors mediating the IPSPs of LS
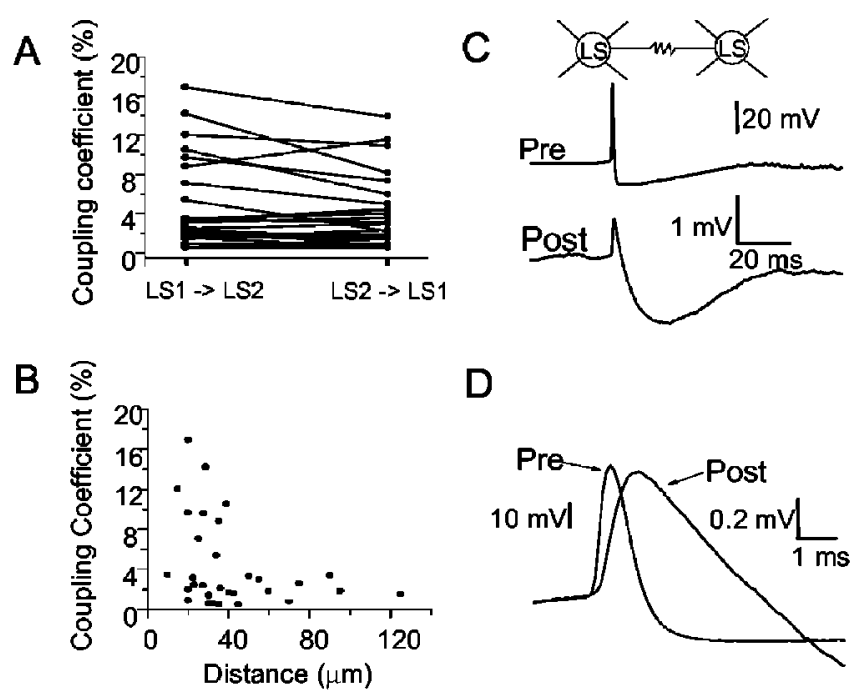

Figure 8. Properties of electrical coupling among layer $1 \mathrm{LS}$ cells. $A$, Electrical coupling was bidirectional. Comparison of step coupling coefficient when current was injected in $\mathrm{LS}_{1}$ versus $\mathrm{LS}_{2}$. B, Step coupling coefficient as a function of the distance between the somata of the two electrically coupled LS cells ( $n=31$ pairs). C, Example of spike transmission in a pair of $L S$ neurons that were connected only via electrical synapses (see Materials and Methods). A prolonged depolarization of the presynaptic cell produced spontaneous action potentials that were transmitted to a postsynaptic neuron as a brief depolarization, followed by a slow hyperpolarization. The holding potential of postsynapticcell was $-75 \mathrm{mV}$. Traces were aligned to the peak of the presynaptic spike and represent the average of 102 trials. The step coupling coefficient was $16.9 \%$, and the spike coupling coefficient was $1.4 \%$. D, Superimposition of the presynaptic spike and the corresponding response in the coupled postsynaptic neuron. The latency between the peak of presynaptic spike (Pre) and the peak of the spikelet or postsynaptic response (Post) was $0.7 \mathrm{msec}$. Data from the same pair as in $C$.

cells are slow compared with the $\mathrm{GABA}_{\mathrm{A}}$ receptors mediating inhibition by FS cells. Connections between LS cells and either LS cells or other layer 1 neurons may also have occurred at dendrites, but anatomic investigation is necessary to determine the synaptic location.

We found that local pyramidal neurons provide excitatory inputs to LS cells. The time course of the EPSCs and EPSPs at pyramidal-to-LS cells is fast (Fig. 3B), suggesting that these synapses are somatic or proximal. In addition to inputs from local pyramidal cells, LS cells could also receive excitatory inputs from other sources, including thalamic nuclei and other cortical areas.

\section{Electrical coupling}

Previous studies suggested that, in the neocortex, electrical coupling may be a specific property of GABAergic neurons and that only cells belonging to the same class are coupled (Galarreta and Hestrin, 1999; Gibson et al., 1999; Tamas et al., 2000; Szabadics et al., 2001; Meyer et al., 2002) (for review, see Galarreta and Hestrin, 2001b). Given that the LS cells in layer 1 are GABAergic, we then asked whether these cells are electrically coupled. Using paired recordings, we demonstrated that $83 \%$ of LS pairs were electrically coupled, whereas pairs consisting of an LS cell and a non-LS cell were only rarely electrically coupled (2\%). Thus, our data support and extend the idea that electrical coupling defines multiple networks of GABAergic neurons embedded within the neocortex.

The general properties of the electrical coupling among LS cells, including the coupling strength, are similar to those among FS and low-threshold spiking (LTS) cells (Galarreta and Hestrin, 2001b). It has been shown that the neuron-specific connexin Cx36 underlies electrical coupling among FS and LTS cells 
(Deans et al., 2001; Hormuzdi et al., 2001). Whether Cx36 is expressed in LS cells needs to be determined. We did not observe dye coupling among layer 1 neurons when we included biocytin in our recording pipettes (but see Benardo, 1997). Lack of dye coupling among electrically coupled cells has been observed previously (Gibson et al., 1999) (for review, see Galarreta and Hestrin, 2001b) and may be related to the low conductance of individual gap junction channels (Srinivas et al., 1999).

\section{Functional implications}

Excitatory inputs at layer 1 include axons originating from specific and nonspecific thalamic nuclei, from other cortical areas, and from layer 2-6 pyramidal neurons. The main targets of the excitatory fibers in layer 1 are the apical dendritic tufts of layer 2-6 pyramidal cells. It has been shown that activation of excitatory axons in layer 1 can be very effective in producing dendritic action potentials that propagate anterogradely and influence the activity of pyramidal cells at all cortical layers (Kim and Connors, 1993; Cauller and Connors, 1994; Zhu, 2000). Given that the apical tufts of pyramidal neurons in layer 1 may act as a spike initiation zone (Oakley et al., 2001; Larkum and Zhu, 2002), local inhibition in layer 1 could play an important role in governing the generation and propagation of action potentials in this zone. The axons of some inhibitory neurons in layers 2-6, including Martinotti cells, ascend to layer 1 , and thus, inhibition at layer 1 is likely to depend on several types of inhibitory cells in addition to the layer 1 LS cells. We showed here that LS cells receive excitatory inputs from local pyramidal cells, but it remains to be determined whether LS cells receive inputs from other excitatory axons in layer 1 . The high degree of electrical coupling among LS cells that we demonstrate here suggests that these cells may be able to synchronize their activity and thus exert powerful control at their postsynaptic targets. Recently, in vivo experiments have shown that activation of layer 1 fibers leads to excitation, followed by inhibitory response (Helmchen et al., 1999; Larkum and Zhu, 2002). Our data suggest that LS cells in layer 1 may contribute to the inhibition observed under physiological conditions.

\section{References}

Anderson JC, Martin KA, Picanco-Diniz CW (1992) The neurons in layer 1 of cat visual cortex. Proc R Soc Lond B Biol Sci 248:27-33.

Beaulieu C, Kisvarday Z, Somogyi P, Cynader M, Cowey A (1992) Quantitative distribution of GABA-immunopositive and -immunonegative neurons and synapses in the monkey striate cortex (area 17). Cereb Cortex 2:295-309.

Benardo LS (1997) Recruitment of GABAergic inhibition and synchronization of inhibitory interneurons in rat neocortex. J Neurophysiol 77:3134-3144.

Budde T, White JA (1998) The voltage-dependent conductances of rat neocortical layer I neurons. Eur J Neurosci 10:2309-2321.

Cauller LJ, Connors BW (1994) Synaptic physiology of horizontal afferents to layer I in slices of rat SI neocortex. J Neurosci 14:751-762.

Cauller LJ, Kulics AT (1991) The neural basis of the behaviorally relevant $\mathrm{N} 1$ component of the somatosensory-evoked potential in SI cortex of awake monkeys: evidence that backward cortical projections signal conscious touch sensation. Exp Brain Res 84:607-619.

Deans MR, Gibson JR, Sellitto C, Connors BW, Paul DL (2001) Synchronous activity of inhibitory networks in neocortex requires electrical synapses containing connexin36. Neuron 31:477-485.

DeFelipe J, Jones EG (1988) Cajal on the cerebral cortex (Fig. 68, p. 158; Fig. 94, p. 208). New York: Oxford UP.

Felleman DJ, Van Essen DC (1991) Distributed hierarchical processing in the primate cerebral cortex. Cereb Cortex 1:1-47.

Gabbott PL, Somogyi P (1986) Quantitative distribution of GABAimmunoreactive neurons in the visual cortex (area 17) of the cat. Exp Brain Res 61:323-331.
Galarreta M, Hestrin S (1999) A network of fast-spiking cells in the neocortex connected by electrical synapses. Nature 402:72-75.

Galarreta M, Hestrin S (2001a) Spike transmission and synchrony detection in networks of GABAergic interneurons. Science 292:2295-2299.

Galarreta M, Hestrin S (2001b) Electrical synapses between GABA-releasing interneurons. Nat Rev Neurosci 2:425-433.

Geiger JR, Lubke J, Roth A, Frotscher M, Jonas P (1997) Submillisecond AMPA receptor-mediated signaling at a principal neuron-interneuron synapse. Neuron 18:1009-1023.

Gibson JR, Beierlein M, Connors BW (1999) Two networks of electrically coupled inhibitory neurons in neocortex. Nature 402:75-79.

Helmchen F, Svoboda K, Denk W, Tank DW (1999) In vivo dendritic calcium dynamics in deep-layer cortical pyramidal neurons. Nat Neurosci 2:989-996.

Hestrin S, Armstrong WE (1996) Morphology and physiology of cortical neurons in layer I. J Neurosci 16:5290-5300.

Hormuzdi SG, Pais I, LeBeau FE, Towers SK, Rozov A, Buhl EH, Whittington MA, Monyer H (2001) Impaired electrical signaling disrupts gamma frequency oscillations in connexin 36-deficient mice. Neuron 31:487-495.

Jones EG (1984) Neurogliaform or spiderweb cells. In: Cerebral cortex (Peters A, Jones E, eds), pp 409-418. New York: Plenum.

Kawaguchi Y (1995) Physiological subgroups of nonpyramidal cells with specific morphological characteristics in layer II/III of rat frontal cortex. J Neurosci 15:2638-2655.

Kawaguchi Y, Kubota Y (1997) GABAergic cell subtypes and their synaptic connections in rat frontal cortex. Cereb Cortex 7:476-486.

Kim HG, Connors BW (1993) Apical dendrites of the neocortex: correlation between sodium- and calcium-dependent spiking and pyramidal cell morphology. J Neurosci 13:5301-5311.

Larkum ME, Zhu JJ (2002) Signaling of layer 1 whisker-evoked $\mathrm{Ca}^{2+}$ and $\mathrm{Na}^{+}$action potentials in distal and terminal dendrites of rat neocortical pyramidal neurons in vitro and in vivo. J Neurosci 22:6991-7005.

Li J, Schwark HD (1994) Distribution and proportions of GABAimmunoreactive neurons in cat primary somatosensory cortex. J Comp Neurol 343:353-361.

Llinas RR, Leznik E, Urbano FJ (2002) Temporal binding via cortical coincidence detection of specific and nonspecific thalamocortical inputs: a voltage-dependent dye-imaging study in mouse brain slices. Proc Natl Acad Sci USA 99:449-454.

Martin KA, Friedlander MJ, Alones V (1989) Physiological, morphological, and cytochemical characteristics of a layer 1 neuron in cat striate cortex. J Comp Neurol 282:404-414.

Meyer AH, Katona I, Blatow M, Rozov A, Monyer H (2002) In vivo labeling of parvalbumin-positive interneurons and analysis of electrical coupling in identified neurons. J Neurosci 22:7055-7064.

Mitchell BD, Cauller LJ (2001) Corticocortical and thalamocortical projections to layer I of the frontal neocortex in rats. Brain Res 921:68-77.

Oakley JC, Schwindt PC, Crill WE (2001) Initiation and propagation of regenerative $\mathrm{Ca}^{2+}$-dependent potentials in dendrites of layer 5 pyramidal neurons. J Neurophysiol 86:503-513.

Srinivas M, Rozental R, Kojima T, Dermietzel R, Mehler M, Condorelli DF, Kessler JA, Spray DC (1999) Functional properties of channels formed by the neuronal gap junction protein connexin36. J Neurosci 19:9848-9855.

Szabadics J, Lorincz A, Tamas G (2001) Beta and gamma frequency synchronization by dendritic GABAergic synapses and gap junctions in a network of cortical interneurons. J Neurosci 21:5824-5831.

Tamas G, Buhl EH, Lorincz A, Somogyi P (2000) Proximally targeted GABAergic synapses and gap junctions synchronize cortical interneurons. Nat Neurosci 3:366-371.

Vogt BA (1991) The role of layer I in cortical function. In: Cerebral cortex (Peters A, Jones E, eds), pp 49-79. New York: Plenum.

Winer JA, Larue DT (1989) Populations of GABAergic neurons and axons in layer I of rat auditory cortex. Neuroscience 33:499-515.

Zhou FM, Hablitz JJ (1996a) Morphological properties of intracellularly labeled layer I neurons in rat neocortex. J Comp Neurol 376:198-213.

Zhou FM, Hablitz JJ (1996b) Layer I neurons of rat neocortex. I. Action potential and repetitive firing properties. J Neurophysiol 76:651-667.

Zhou FM, Hablitz JJ (1997) Rapid kinetics and inward rectification of miniature EPSCs in layer I neurons of rat neocortex. J Neurophysiol 77:2416-2426.

Zhu JJ (2000) Maturation of layer 5 neocortical pyramidal neurons: amplifying salient layer 1 and layer 4 inputs by $\mathrm{Ca}^{2+}$ action potentials in adult rat tuft dendrites. J Physiol 526:571-587. 